\title{
Social tourism carrying capacity in Kampung Kilim, World Geopark, Langkawi
}

\author{
K. Kayat ${ }^{1} \&$ R. Mohd Radzi ${ }^{2}$ \\ ${ }^{I}$ School of Tourism, Hospitality and Environmental Management, \\ Universiti Utara Malaysia, Malaysia \\ ${ }^{2}$ Department of Hospitality Management, \\ Tengku Syed Sirajuddin Polytechnic, Perlis, Malaysia
}

\begin{abstract}
The World Geopark status given to Langkawi by UNESCO has accelerated growth of tourist arrivals to the island since 2007. This paper explores Kilim resident tolerance level in the context of social tourism carrying capacity for the development of the Langkawi Geopark. Kilim is chosen as a case in this study as it is located close to a nature park which is one of the main elements in this World Geopark. The intent is to highlight the social aspects of contemporary destination growth that need greater attention by policy makers and planners. Findings from the study indicate that although tourism is changing residents' traditional values, residents want to see more tourists in Langkawi.

Keywords: social tourism carrying capacity, tolerance level, resident attitudes, tourism social impacts, Langkawi, Malaysia.
\end{abstract}

\section{Introduction}

Tourism carrying capacity is an important parameter within the sustainable approach of tourism development as it is concerned with the level of tourism development that an area can accommodate without the area deteriorating in terms of its physical environment, the resident community being negatively affected or the quality of visitors experience declining [1, 2]. Tourism development that is sensitive towards the area carrying capacity ensures that tourism is developed in a sustainable manner.

The social component of carrying capacity refers to the social threshold at which negative effects of development of the area for the purpose of tourism, 
with respect to people, will begin to be felt. In tourism, the two main groups of people are the hosts (residents) and the guest (tourists). Thus, social component of tourism carrying capacity is about ensuring quality of life for residents and quality of visitor experience. Sustainable tourism, therefore, is not about the quantity of tourism, but about the quality of tourism. This paper focuses on the social component of carrying capacity pertaining to the first group of people, the residents (hosts).

Kilim Karst Geoforest Park is one of the three main conservation areas in Langkawi Geopark; the other two are Machincang Cambrian Geoforest Park and Dayang Bunting Marble Geoforest park. In addition, there are also limestone caves in the mangrove. The area experience accelerated growth in visitor arrivals since 2007. The residents in Kampung Kilim (Kilim Village) are connected to and affected by tourism in this area as the Kilim Jetty, which is the main entry point to Kilim Karst Geoforest Park, is within their residential area. This paper is not about determining the carrying capacity of tourism in a tourism area within the Langkawi Geopark, but to share the findings from a case study in the area that share the tolerance level of the residents as it relate to the concept of social carrying capacity.

\subsection{The concept of social carrying capacity and tolerance level}

Tourism should be developed in such a way that the social impacts are tolerable by the residents i.e. the destination must have the capacity to accept or tolerate the impacts before the social impacts produce negative consequences - a concept named as the social component of tourism carrying capacity. Measuring this capacity or this threshold level is a vital planning and monitoring strategy. Examples of negative consequences from social impacts of tourism are erosion of the social fabric and cultural alienation. Doxey [3] proposed that a threshold level between community acceptance of tourism and community rejection of tourism is explained by the stress levels due to tourism created within a community in his Irridex model which recognizes that unfavorable impacts of tourism development may lead to irritation in the community. The increase in the number of tourists and the increase in the intensity of the development of a tourist destination have an effect on residents' perception that move from euphoria (low irritation) to apathy, annoyance and finally to antagonism (high irritation).

\subsection{Evaluating resident tolerance level in tourism development}

Resident tolerance level in tourism development is the level of use of tourism resources that can be absorbed by an area without an unacceptable adverse impact on the residents in that area. According to Saveriades [4], social capacity thresholds are perhaps the most difficult to evaluate as opposed to environmental, cultural and economic capacity thresholds since they rely entirely on value judgments.

Unlike the environmental and economic capacity thresholds which can be measured through the actual impact parameters or through evaluative standards, 
social capacity threshold can only be measured using the evaluative standards. The impact parameters are the objective measurements of the effects of tourism activity such as the amount of noise in decibels (impact parameter for environmental threshold), the extent of pollution in the water (impact parameter for environmental threshold) and total employment created by the tourism sector (impact parameter for economic threshold). The evaluative standards, on the other hand, determine the level of impact that is acceptable or most desirable.

According to Shelby [5], evaluative standards are "yardsticks for determining how much is too much" which rely on value judgments as opposed to impact parameters which are objective measurements. When value judgments give an indication that the impacts from tourism development is too much that the quality of life of those residing in the destination begins to be eroded, then we can say that the sociological carrying capacity for tourism development in that area has been exceeded.

Several previous studies on resident attitudes toward tourism (see for example Glasson and Godfrey [6] and Long and Kayat [9]) indicate that those who were more dependent on tourism were more positive about tourism development in their residential area than those who were not. Kayat labels those who were dependent on tourism as those who were powerless party in the tourism-resident exchanges. Strang [8] explains that economic restructuring and decline in industry has led to tourism forming a very important component of many New Zealand towns' economies.

\section{The research problem, definition of terms and research question}

Reactions of a destination's residents toward tourism depend of its unique local characteristics [9]. This paper attempts to expand this knowledge by synthesizing results from a case study undertaken to study the applicability of resident tolerance level within the tourism carrying capacity concept as a management tool for Langkawi tourism development. The study focuses on the role played by residents' dependency on tourism in the formation of this tolerance level.

Resident tolerance level is operationally defined as the level of tourism development in Kampung Kilim that is tolerated by its residents without an unacceptable negative impact on the residents in that area. Meanwhile, the operational definition for dependency on tourism is the degree of residents' reliance on tourism for their living. The research question that guides this study is "how do the current residents in Kampung Kilim tolerate tourism development in their area?"

\section{Methodology}

A case study approach has been used in this study. The case study is a part of a wider study aiming to establish a sustainable rural tourism framework for Langkawi. Case study typically seeks to answer questions beginning with how or why. In this case study, unstructured interviews and document reviews were used 
as techniques to understand the phenomenon under study. The researchers based themselves in the community for approximately one month, canvassing general opinions, having non-formal conversations and conducting formal interviews with key members of the community. The non-formal conversations resulted in names and addresses of potential respondents being secured. Attempts were made to recruit interview respondents that were dependent as well as those who were not dependent on tourism. At the end, 30 respondents were interviewed.

The questions posed to the interview respondents reflected the purpose of the research, namely:

1. How dependent are Kilim residents on tourism in Kilim and Langkawi.

2. What Kilim residents like about tourism in Kilim and Langkawi.

3. What Kilim residents do not like about tourism in Kilim and Langkawi.

4. What Kilim residents think about limiting tourist arrivals to Kilim and Langkawi.

The primary data of the individual in-depth interviews were audiotape recorded and later transcribed. The transcripts were then translated from Malay to English. To retain the meaning of the statements and ideas contained in the transcripts, word-to-word translation was avoided. Instead, translation was made on each sentence. These translated transcripts became the data used in data analysis.

\section{Analysis}

Langkawi's success in tourism is commonly connected to the legendary local beauty, Mahsuri, who put Langkawi under a curse when she was condemned to death for not being faithful to her husband while he was away at war against the Siam. Lifting her hands to the sky, Mahsuri presaged that prosperity would elude Langkawi for seven generations to come [10]. Soon after her death, Langkawi did observe a decline in prosperity, as described by a local historian, "...even grass refused to grow on the island" (Mohamad Shariff p. 34) [11]. The prosperity due to the aggressive tourism development could have marked the end of the legendary curse.

Kampung Kilim is a village in the Ayer Hangat District in Langkawi. The name Ayer Hangat, which literally means hot water, is given to the district due to the existence of a well with hot water in the district. The first dwellers of the district came from the Southern parts of Thailand about 150 years ago. The main economic activity in the village has turned from fishing and farming to providing tourist services especially in the form of boat and guides services to tourists visiting the mangroves, the Nature Park, and islands through the Kilim River Cruise.

The declaration and the inception of the Langkawi Development Authority (LADA) in 1990 has brought systematic development to these legendary cursed islands and transformed them into the present day modern tourist destination. In 2006, Langkawi was declared as a Geopark by the state of Kedah and Langkawi Geopark was accepted as the 52nd member of Global Geopark Network (GGN) in 2007. GGN is network under the auspices of UNESCO. The membership 
of Langkawi Geopark in GGN was extended from the period of 2007-2011 to 2015 [12].

Tourist arrivals to Kilim Karst Geoforest Park grew tremendously since it was declared a Geopark in 2007. In 2010, the number of arrivals recorded was 117,931 which is about $178 \%$ more than what was recorded in 2006 when only 42,375 was recorded [13]. Tourist arrivals to Langkawi as a whole also have also been increasing since 2006 and it is thought that the Geopark status has contributed to this growth.

\subsection{Residents' dependency on tourism}

The results of the data analysis from the in-depth interviews yielded two main themes indicating that respondents are dependent on tourism in their lives either because their income depended on it or because Langkawi's development is influenced by tourism. Twenty of the respondents interviewed either worked in tourism-related employment or were running businesses that were frequented by tourists. Their dependencies on tourism are indicated by their explanations that tourism brings income personally to them:

"The tourists come and eat at my warung (stall), so I get some money from them." (Soup Noodle stall operator).

"My income depends on them (tourists); it will be hard if we don't have them (tourists)." (Souvenir shop operator).

"I work in the tourism industry; they are part of my job." (A chef working in a hotel).

"Like me, I work with the hotel, the more tourists checking in this hotel means more points for me". (Hotel employee).

Four of the respondents worked with government departments which were unrelated to tourism, three respondents were fishermen and three respondents or were unemployed. All of them indicate that Langkawi's progress and development depend on tourism:

"Tourism causes many hotels being built..This is good for Langkawi." (Government Officer)

"If the tourists stop coming here, Langkawi's economy will be affected badly" (Fisherman)

"We must let them keep coming, if not the people here...their economy will be affected" (Housewife).

\subsection{Residents' tolerance level}

Effort was made to understand the benefits and costs from tourism that are felt by the residents and how they perceive these benefits and costs. Thus, respondents are asked to talk about what they like and what they do not like about tourism in Kilim and in Langkawi. Five themes surfaced regarding what Kilim residents like about tourism:

a. All respondents like the fact that tourism improves residents' economy.

b. Several of them approve its effect on their standard of living through better infrastructure. 
c. Tourism makes Langkawi known to the outside world.

d. Tourism allows residents to improve their communication skill.

e. Tourism creates self-development opportunity.

It needs to be highlighted that not one of the respondents gives any indication on their knowledge about the benefits that tourism had brought to the environment. The following excerpts are affidavits for the above themes:

"We can see the improvement in the economic status of our people, many of them are living comfortably, and their houses are now big".

"There are so many things the government did to Langkawi that have made Langkawi more popular to the world, and that is not an easy task"

"The changes that we can see now, many hotels have been built, many work opportunities in this area. Young people have no need to migrate out to find jobs now."

"I did not know how to speak English before, but now I can. Also, the roads in the village are better now. Tourism also provides jobs to the young people here."

"People in Kilim and Langkawi are more advanced now; their minds are more open now...it is much better now."

"Tourism has educated us, like, we now know about what Geopark means..."

"Many people in Langkawi now know how to earn money now, how to take opportunities up to their advantage, like doing different kinds of business, many are industrious now."

"Many are now better off than before, our kids can now have study in higher education levels."

Analysis on what Kilim residents don't like about tourism produces five main themes:
a. Tourism causes changes in values and lifestyles.
b. Tourism brings about business competition.
c. Tourism brings about overcrowding.
d. Tourists litter the place.
e. Tourism brings about high costs of living.

The analysis did not find any tourism outcomes related to the environment that the respondents did not like. The following excerpts are affidavits for the above themes:

"I notice that those who work in the hotels, they do not have time to mix with their neighbours, maybe this is because they have to work in shifts."

"What I do not like about them is that they like to throw trash and litter the place. But this is only among the domestic tourists. Those from outside Malaysia, they do not do the littering."

"Some tourists drive their vehicles without giving attention to the law."

"Tourism makes the price of food go up. And they, the domestic tourists, not the foreigners, they throw rubbish anywhere they like, litter the place."

"There are many more people doing businesses here, this creates competition to me...its becoming competitive, becomes hard."

"I do not like the fact that our standard of living has increased because Langkawi now has become a tourist place."

"The Malays here, many like to follow the foreigners' culture and style." 
"Many locals try to dress like the foreign tourists, which is not good, not our culture."

"One thing I do not like is that, Langkawi has became like Kuala Lumpur, it is so congested now especially during the school holidays."

"The influence from the tourists to is actually very bad, in terms of the way our people try to behave like them."

An interesting finding is that several respondents exerts that the negative impacts are still under control thus are tolerable especially because they put high value on the economic benefits from tourism. A respondent (a hotel front office staff) shared her thoughts, "The tourists, yes, their clothing, and the way they dress, they can be provocative, but they come and they go. They give income to me. I agree to have tourists here." A taxi driver gave a similar view, "About the social aspect, I do not like that our people adopt the foreigners' culture; some of them even marry these outsiders. If tourists make our youngsters to become better, then it is ok. But now, even if they are still Islam, they way they dress is not Islamic, and this is not good. But, it is not good if we stop tourists from coming because they are our source of rezeki (livelihood)." A pious older villager seems to not be in favour of the cultural impact from tourism, "I once saw a girl smoking just like them (the tourists), she does not care about us looking at her like that. And, now, we have discos especially in Cenang where the foreigners get drunk." However, he added, "But, let them still come, only we need not follow they style which is bad style."

There are also respondents that indicate that they have no qualms over the social problems from tourism. As an example a respondent made a remark, "Tourism brings so many good things economically. Other things, I do not really know" Another seems like he was trying to pacify himself about the problem. "All that (changes of cultural values), they happen anywhere, not just in Langkawi," he explained. Another respondent simply answered "Never" when asked if he has ever come across with the problem.

\subsection{Residents' attitudes toward a limit on tourism}

One unambiguous theme came out from the analysis on what Kilim residents think about limiting tourist arrivals; all those interviewed did not think tourists and tourism in Langkawi should be limited. Examples of excerpts supporting this finding are as follows:

"I do not feel we have to limit tourism, it is the source of income to those with business."

"Do not limit the tourist; it will affect the residents' income. Langkawi can still contain the tourists."

"More tourists is better, they are our source of income."

"Why limit the tourists? They bring no harm to us."

"I am old, I hate seeing the tourists, some of them only where their underwear and walk around. But they bring money to us, so, no.... we should not stop them from coming to Langkawi." 


\section{Conclusions}

Prevailing themes emerged from the data analysis indicating that tourism in Kilim is tolerated by its residents as the negative impacts it produces are still tolerable. They are also becoming used to tourists and the tourists lifestyle. Tourism has clearly become an important component of Langkawi economy. The residents' dependence on tourism creates a tradeoff of the negative effects of tourism against the personal and community gains, much like what was found by Teye and Sonmez [14]. In addition, it can be concluded that there appears to be high levels of altruism being expressed about tourism as tourism is highly regarded as a benefit to the Island because of the perceptions that it created jobs and incomes for the people even if respondents did not indicate any personal benefits.

Although the respondents strongly indicated that tourism in Kilim and Langkawi should not be halted due to what it produces socially, areas such as foreigners behavior in regards to respecting local culture and values, tourist behavior in terms of cleanliness and comfort and locals appreciation of traditional culture and values need to be given attention. It seems the community is happy for tourism to progress, as long they perceive that it is under control, as long as they can benefit from it economically and as long as they can still live comfortably.

The study did not discover much on residents' sensitivity toward environmental risks that are commonly related to tourism. However, future study may need to tap on this area as Kayat [15] had discovered that many residents with high dependence on tourism are not aware of the fragility of the ecosystems visited by the tourists thus they do not 'ask' for the monitoring of the negative impacts to the environment. Although the study did not find the community to be protective of its environment as much as they are protective of their economy and cultural values, the planners and the management must not conclude that there are no adverse impacts to the environment. It may actually mean that their appreciation and understanding of the environment are still lacking.

For a geopark tourism destination such as Langkawi to grow in a sustainable manner, controls must be secure in place. This includes management and planning regimes and policies that are sensitive to environment, social and community impacts, whilst incorporating effective marketing strategies to bring in the rewards, and simultaneously minimize the negative impacts. Community attitudes toward tourism activities and development in Kilim Karst and Langkawi reveal that they want to see more development. However, as cautioned by Mason and Cheyne [16], community attitudes towards tourism development are very complex in nature, thus acting upon these attitudes is not a simple task for the planners.

Social carrying capacity framework is still being studied and discussed in the tourism literature. As an example, it has been understood that if a destination such as Langkawi Geopark attracts more and more tourists over time with no controls, the destination will move through stages of development until it eventually declines because of a degradation of its resources [17]. However, 
many factors may influence social carrying capacity and tolerance level among residents; this study finds that economic dependency is one of the probable factors. This is a work in progress and further in-depth analysis of the raw data gathered in this case study is required to establish a framework for Kampung Kilim. The importance and effect of tourism to the residents require further investigation as to enable planners to manage the impacts brought by tourists during their interactions with residents.

\section{Acknowledgement}

This paper is an outcome of an ongoing research that is fully funded by the Ministry of Higher Education, Malaysia under the Long-term Research Grant Scheme.

\section{References}

[1] Simon, F.J.G., Narangajavana, Y. and Marques, D.P. Carrying capacity in the tourism industry: a case study of Hengistbury Head. Tourism Management, 25(2), pp. 275-283, (2004).

[2] Lawson, R.W., Williams, J., Young, T. and Cossens, J. A comparison of residents attitudes towards tourism in 10 New Zealand destinations. Tourism Management, 19(3), pp. 247-256, (1998).

[3] Doxey, G. V. A causation theory of visitor-resident irritants; methodology and research inferences. Sixth Annual Travel Research Conference, San Diego, Ca, September 8-11, pp. 195-198, (1975).

[4] Saveriades, A. Establishing the social tourism carrying capacity for the tourist resorts of the east coast of the Republic of Cyprus. Tourism Management, 21(2), pp, 147-156, (2000).

[5] Shelby, B. (1987). Carrying Capacity in Recreational Settings. Oregon: Oregon State University Press, p.16.

[6] Glasson, J. and Godfrey, K. Towards Visitor Impact Management: Visitor Impacts, Carrying Capacity and Management Responses in Europe's Historic Towns and Cities. Aldershot: Averbury Publishing Limited, (1995).

[7] Kayat, K. Power, social exchanges and tourism in Langkawi: Rethinking resident perceptions. International Journal of Tourism Research, 4(3), pp. 177-191, (2002).

[8] Strang, R. Investigations into the Application of Carrying Capacity Concept for Four New Zealand Settings. Social Science Research Centre, University of Canterbury. Retrieved May 5, 2012 from http://www.ssrc.canterbury.ac.nz/research/2003-4/investigation_RS.pdf. (2003).

[9] Long, P.H. and Kayat, K. Residents' sosio-demographic characteristics, their perception of tourism impacts and their support for tourism development: A case study of Cucphuong National Park, Ninh Binh 
Province, Vietnam. European Journal of Tourism Research, 4(2), pp. 217 230, (2011).

[10] North Review. Langkawi Soars to Greater Heights. Published brochure. Alor Setar Kedah: The State Government of Kedah, (1995).

[11] Mohamad Shariff, R. Versi-versi Mahsuri dalam Konteks Socio-Budaya dan Perbandingan. Unpublished B.A. Thesis. Kuala Lumpur: Universiti Malaya, pg. 34, (1980).

[12] Sharina Abdul Halim, Ong Puay Liu, Norzaini Osman, Ibrahim Komoo, Rahimah Abdul Aziz, Sarah Aziz, Geraldine Chan, Halimaton Saadiah Hashim, and Ruslin Halim. Understanding the meaning of Geopark and heritage conservation from local perspectives: views from two fishing villages in Langkawi, Kedah, Malaysia. Paper presented in Simposium Kebangsaan Warisan dan Pemuliharaan organized by Projek Arus Perdana, Geopark sebagai Peraga Pembangunan Lestari Wilayah, Kelompok Warisan dan Pemuliharaan, Nic Pembangunan Lestari Wilayah, 26-28 February, Awana Porto Malai, Langkawi, (2010).

[13] Langkawi Development Authority. Retrieved May 5, 2012 from http://www.lada.gov.my, (2012).

[14] Teye, V. and Sonmez, S. Resident's attitudes towards tourism development. Annals of Tourism Research, 29(3), pp. 668-688, (2002).

[15] Kayat, K. Power, social exchanges and tourism in Langkawi: Rethinking resident perceptions. International Journal of Tourism Research, 4(3), pp, 177-191, (2002).

[16] Mason, P. and Cheyne, J. Residents' attitudes to proposed tourism development. Annals of Tourism Research, 27(2), pp 391-411, (2000).

[17] Butler, R. W. The concept of a tourism areas cycle of evaluation: Implications for management of resources. Canadian Geographer, 24(1), pp. 5-12, (1980). 